\title{
Direct Evidences for Single Molybdenum Atoms Incorporated in the Framework of MFI Zeolite Nanocrystals
}

\author{
Florent Dubray ${ }^{\dagger}$, Simona Moldovan ${ }^{\ddagger}$, Cassandre Kouvatas $^{\dagger}$, Julien Grand ${ }^{\dagger}, \|$, Cindy Aquino $\|$, \\ Nicolas Barrier ${ }^{\dagger}$, Jean-Pierre Gilson ${ }^{\dagger}$, Nikolai Nesterenko", Delphine Minoux", Svetlana \\ Mintova ${ }^{\dagger, *}$

\begin{abstract}
†Normandie Université, ENSICAEN, UNICAEN, CNRS, Laboratoire Catalyse et Spectrochimie (LCS), 14000 Caen, France łInstitut des Sciences Appliquées de Rouen, Rouen University, Groupe de Physique des Matériaux (GPM), 76801 Rouen, France $\|$ Total Research and Technologies, Feluy, B-7181 Seneffe, Belgium

†Normandie Université, ENSICAEN, UNICAEN, CNRS, Laboratoire de Cristallographie et Science des Matériaux (CRISMAT), Caen, France
\end{abstract}

\section{Synthesis}

Mo-MFI-P and Mo-MFI-D zeolite samples were synthesized using the following chemicals without any further purification: tetraethyl orthosilicate (TEOS, 98\%, Aldrich), tetra n-propylammonium hydroxide (TPAOH, 20 wt. \% in water solution, Alfa Aesar), and sodium molybdate dihydrate $\left(\mathrm{Na}_{2} \mathrm{MoO}_{4} .2 \mathrm{H}_{2} \mathrm{O}\right.$, Alfa Aesar, $\left.98 \%\right)$. Double deionized water was used in the synthesis and post-synthetic treatments. Syntheses were carried out in $125 \mathrm{~mL}$ polypropylene (PP) bottles at autogenous pressure, without agitation. Two different precursor suspensions were prepared with the following molar compositions:

(1) $1 \mathrm{SiO}_{2}: 0.28 \mathrm{TPAOH}: 40 \mathrm{H}_{2} \mathrm{O}$

(2) $1 \mathrm{SiO}_{2}: 0.28 \mathrm{TPAOH}: 40 \mathrm{H}_{2} \mathrm{O}: 0.08 \mathrm{MoO}_{3}$

The resulting clear suspensions were stirred for $1 \mathrm{~h}$ at room temperature, further hydrolysed for $18 \mathrm{~h}$ on an orbital shaker and the hydrothermal synthesis took place at $90^{\circ} \mathrm{C}$ for $48 \mathrm{~h}$. The harvested crystalline products were purified using high speed centrifugation $(20,000 \mathrm{rpm})$ until a pH of 7 was reached, and subsequently dried at $80^{\circ} \mathrm{C}$. The samples were then calcinated in a muffle furnace at $550{ }^{\circ} \mathrm{C}$ for $5 \mathrm{~h}$ prior any post treatment.

The zeolite obtained from suspension (1) was then loaded with molybdenum by wet impregnation with $\mathrm{Na}_{2} \mathrm{MoO}_{4}(700 \mathrm{mg}$ zeolite $/ \mathrm{mL}$ of molybdate solution at $1.5 \mathrm{mg} / \mathrm{mL})$, dried at room temperature and calcined $\left(550^{\circ} \mathrm{C}, 5 \mathrm{~h}\right)$. Its $\mathrm{H}$-form was obtained by ion-exchange of the zeolite twice in a $\mathrm{NH}_{4} \mathrm{Cl}$ solution $(0.2 \mathrm{M})$ for $1 \mathrm{~h}$, washed once with water, dried at $80{ }^{\circ} \mathrm{C}$ and calcined $\left(550^{\circ} \mathrm{C}, 5 \mathrm{~h}\right.$ ); this reference sample was labelled as Mo-MFI-P (i.e. MFI with Mo atoms introduced in a post-synthetic step).

The $\mathrm{H}$-form of the zeolite obtained from suspension (2) was prepared by ion-exchange with a $\mathrm{NH}_{4} \mathrm{Cl}$ solution $(0.2 \mathrm{M})$ for $1 \mathrm{~h}$, and this procedure was repeated. The sample was then washed with water, dried at $80^{\circ} \mathrm{C}$ and calcined $\left(550^{\circ} \mathrm{C}, 5 \mathrm{~h}\right.$ ); this sample was labelled as MoMFI-D (MFI with Mo introduced during the hydrothermal synthesis). 


\section{Characterization}

Powder X-ray diffraction (XRD) patterns of the zeolites were collected with a PANalytical X'Pert Pro diffractometer equipped with a Johansson monochromator using the Cu Ka1 radiation $(\lambda=1.540598 \AA)$. The unit cell parameters, volume, and space group of MoMFI-P and Mo-MFI-D were obtained from a Le Bail profile refinements using the JANA2006 software. ${ }^{1}$

The crystallinity and defects of nanosized zeolites were determined by ${ }^{29} \mathrm{Si}$ and $\left\{{ }^{1} \mathrm{H}{ }^{29} \mathrm{Si}\right.$ cross-polarization (CP) solid-state MAS NMR on a Bruker Avance III-HD 500 (11.7 T) spectrometer operating at $99.3 \mathrm{MHz}$, using a zirconia rotor of $4 \mathrm{~mm}$ outer diameter spun at 12 $\mathrm{kHz}$. For ${ }^{29} \mathrm{Si}$ MAS NMR, a single pulse excitation ( $30^{\circ}$ flip angle) was used with a recycle delay of $30 \mathrm{~s}$. For $\left\{{ }^{1} \mathrm{H}{ }^{29} \mathrm{Si}\right.$ CP-MAS NMR, a contact time of $5 \mathrm{~ms}$ and a recycle delay of $2 \mathrm{~s}$ were used, respectively. Chemical shifts were referenced to tetramethyl silane (TMS).

The acidity of the Mo-MFI-P and Mo-MFI-D zeolites was characterized by IR spectroscopy using a Nicolet Magna 550-FT-IR spectrometer $\left(4 \mathrm{~cm}^{-1}\right.$ optical resolution). The self-supported wafers $\left(1 \mathrm{~cm}^{2}\right.$, av. $20 \mathrm{mg}$, hydraulic press at $\left.1 \mathrm{~T} / \mathrm{cm}^{2}\right)$ of zeolites were activated at $480{ }^{\circ} \mathrm{C}$ for $3 \mathrm{~h}$ under vacuum (av. $2.5 \times 10^{-6}$ Torr) prior to measurements. Successive small doses (2 to $30 \times 10^{-3} \mathrm{mmol} / \mathrm{g}$ loading range) of acetonitrile $\left(\mathrm{CD}_{3} \mathrm{CN}\right)$ were then adsorbed at room temperature.

The acidity of the Mo-MFI-P and Mo-MFI-D zeolites was also characterized by monitoring the adsorption of trimethylphosphine oxide (TMPO) by ${ }^{31} \mathrm{P}-\mathrm{NMR}$ under ${ }^{1} \mathrm{H}$ decoupling. All preparation steps were conducted under an $\mathrm{Ar}$ atmosphere to prevent any reaction of TMPO with air, and water adsorption on the zeolite. Sodium free samples, videsupra, were dehydrated at $400{ }^{\circ} \mathrm{C}$ under vacuum (av. $4.0 \times 10^{-5} \mathrm{Torr}$ ) while a solution of TMPO dissolved in dichloromethane $\left(\mathrm{CH}_{2} \mathrm{Cl}_{2}\right)$ was prepared. This solution was then added to the dehydrated zeolite sample, and the resulting suspension treated in an ultrasonic bath for 15 min. The suspension was then dried by evaporating dichloromethane under vacuum for $2 \mathrm{~h}$. The TMPO loaded zeolites were then packed in zirconium rotors for ${ }^{31} \mathrm{P}$ MAS NMR characterization. All NMR experiments were performed on a $11.7 \mathrm{~T}$ Bruker Avance 500 spectrometer operating at a frequency of $500.0 \mathrm{MHz}$ and $202.4 \mathrm{MHz}$ for ${ }^{1} \mathrm{H}$ and ${ }^{31} \mathrm{P}$ respectively. All MAS NMR spectra were recorded on a $4 \mathrm{~mm}$ MAS probe-head at a spinning rate of $14 \mathrm{kHz}$. ${ }^{31} \mathrm{P} \pi / 2$ and $\pi$-pulses lengths were 7 and $14 \mu \mathrm{s}$ respectively for all measurements. 1D and 2D ${ }^{31} \mathrm{P}$ MAS NMR experiments were conducted under spinal- $64^{2}{ }^{1} \mathrm{H}$ decoupling using a field strength of $71.2 \mathrm{kHz}$, with a recycle delay were carefully set according to preliminary relaxation time measurements. The single-pulse ${ }^{31} \mathrm{P}$ MAS NMR spectra were acquired with 256 scans. Two-dimensional homonuclear ${ }^{31} \mathrm{P}-{ }^{31} \mathrm{P}$ radio-frequency driven recoupling (RFDR) ${ }^{3}$ experiments were also performed, using 80 scans and $4 \mathrm{~K}$ complex points in the $t_{2}$ dimension. The $t_{1}$ dwell was rotor-synchronized, and 192 time increments were set for 0.2 ms mixing time. ${ }^{31} \mathrm{P}$ and ${ }^{1} \mathrm{H}$ chemical shifts and RF pulses were calibrated on phosphoric acid (85\%) and TMS, respectively.

Raman spectra were collected on a Jobin Yvon Labram 300 confocal Raman spectrometer coupled with a microscope (objective: 50x) and a CCD detector. A $532 \mathrm{~nm}$ wavelength laser was used, and spectra were accumulated 3 times for $60 \mathrm{~s}$ each. 
The crystal size and morphology were measured by transmission electron microscopy (TEM); experiments were carried out on an Analythical double (objective and probe) corrected JEOL ARM200CF equipped with a $100 \mathrm{~mm}$ Centurio EDS detector and a Quantum GIF for the EELS. A probe of $0.1 \mathrm{~nm}$ was used to scan the specimen in STEM mode and Bright Field, and high Angular Annular Dark Field detectors were simultaneously employed for imaging. The camera length was fixed at $8 \mathrm{~cm}$. Two different accelerating voltages of $200 \mathrm{kV}$ and $80 \mathrm{kV}$ were employed in the STEM mode for imaging and chemical analysis, respectively. Owing to the enhanced $Z$ contrast developed at $200 \mathrm{kV}$, this configuration was used for imaging and a high speed scanning protocol $(10 \mu \mathrm{sec} / \mathrm{px})$ was employed in order to minimize the specimen degradation under the beam. To avoid material degradation, the STEM-EDS analytical essays were carried out at $80 \mathrm{kV}$ with a high scanning speed of $3 \mu \mathrm{s} / \mathrm{px}$ and for a mean duration of 60 minutes. A cross-correlation algorithm implemented in the Jeol Analysis Station software was applied every 30 seconds in an effort to compensate for the special drift occurring during the test. The microstructure of samples was checked prior and after each EDS scan.

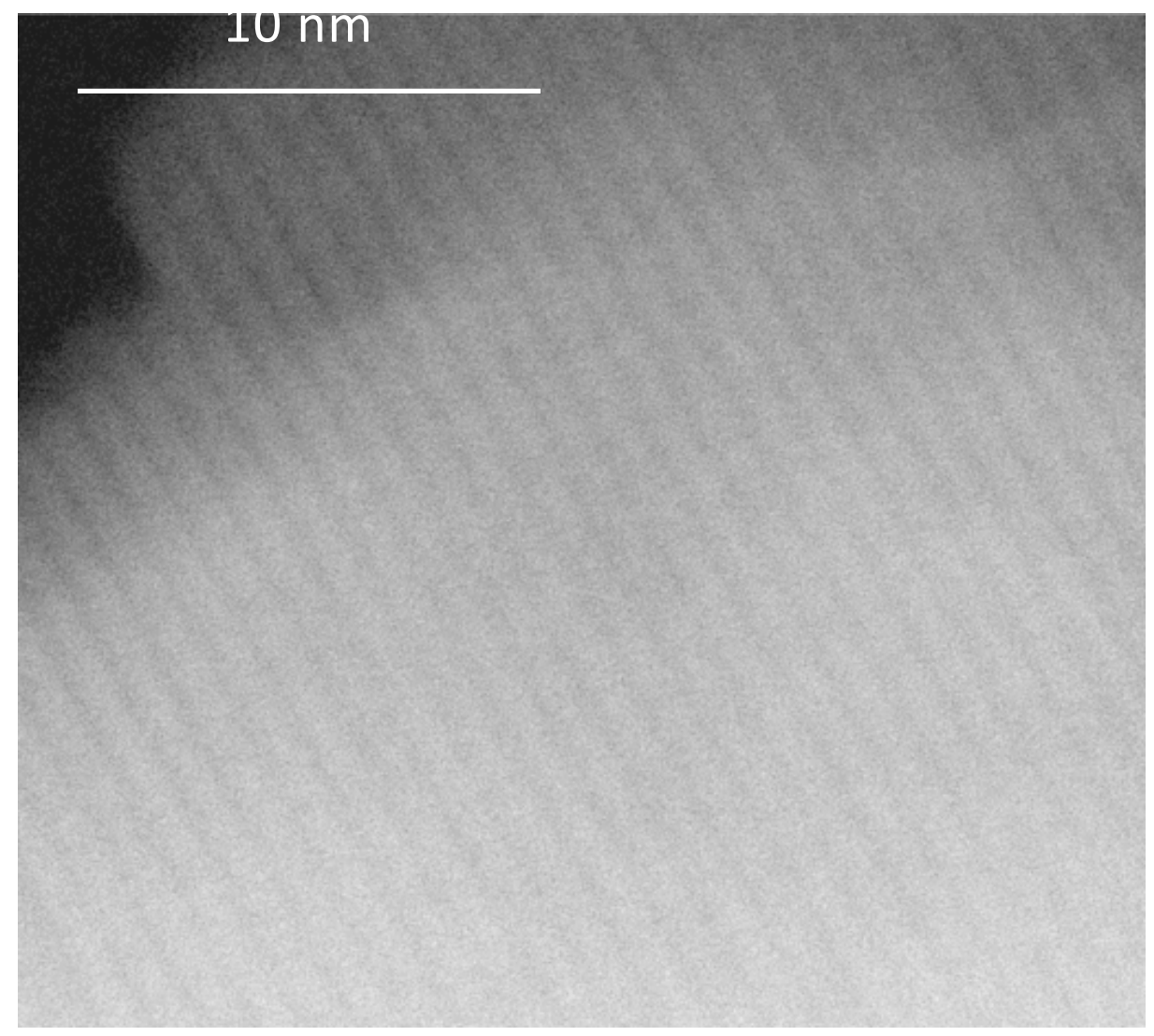

Figure S1. STEM-HAADF micrograph of pure siliceous calcined MFI zeolite prior Mo introduction by ion exchange. 


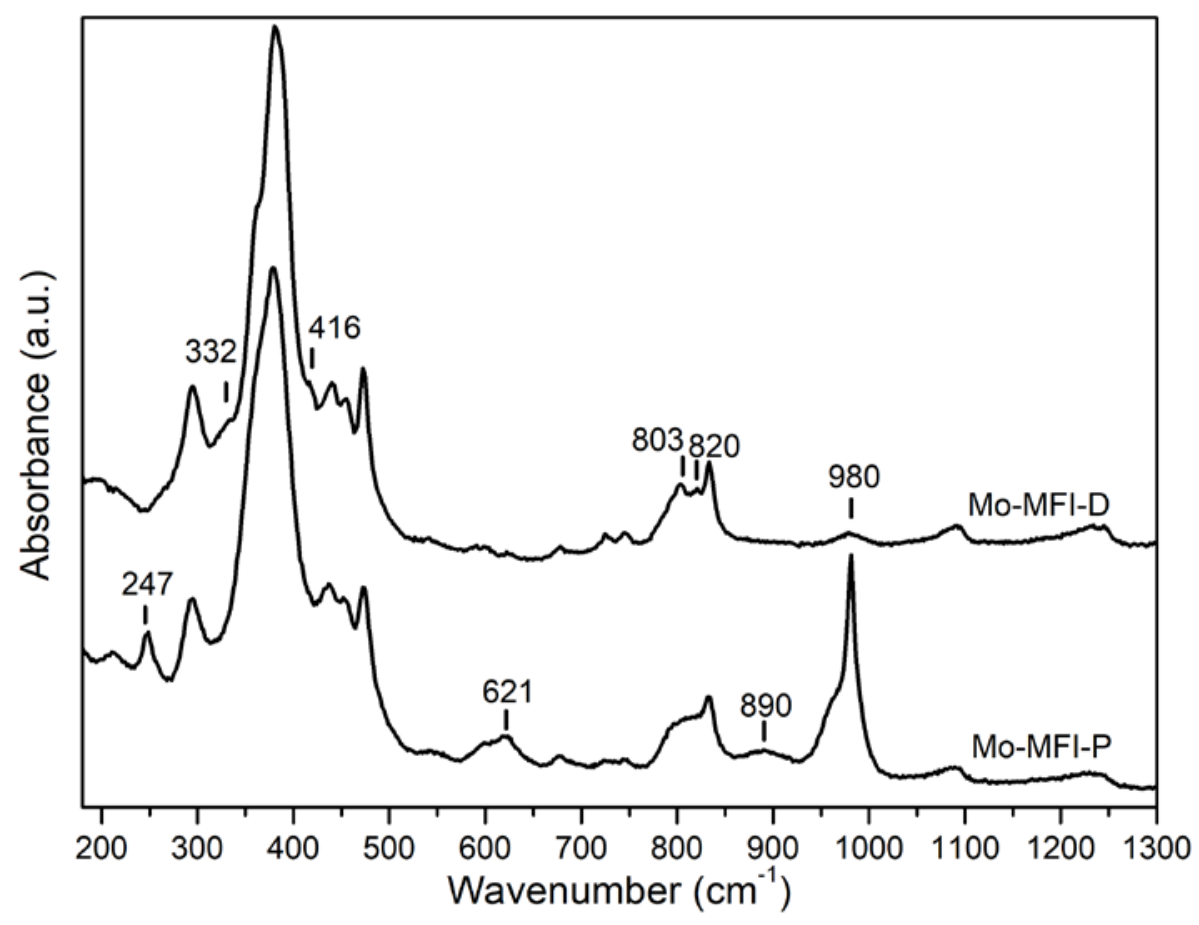

Figure S2. Raman spectra of samples Mo-MFI-P and Mo-MFI-D

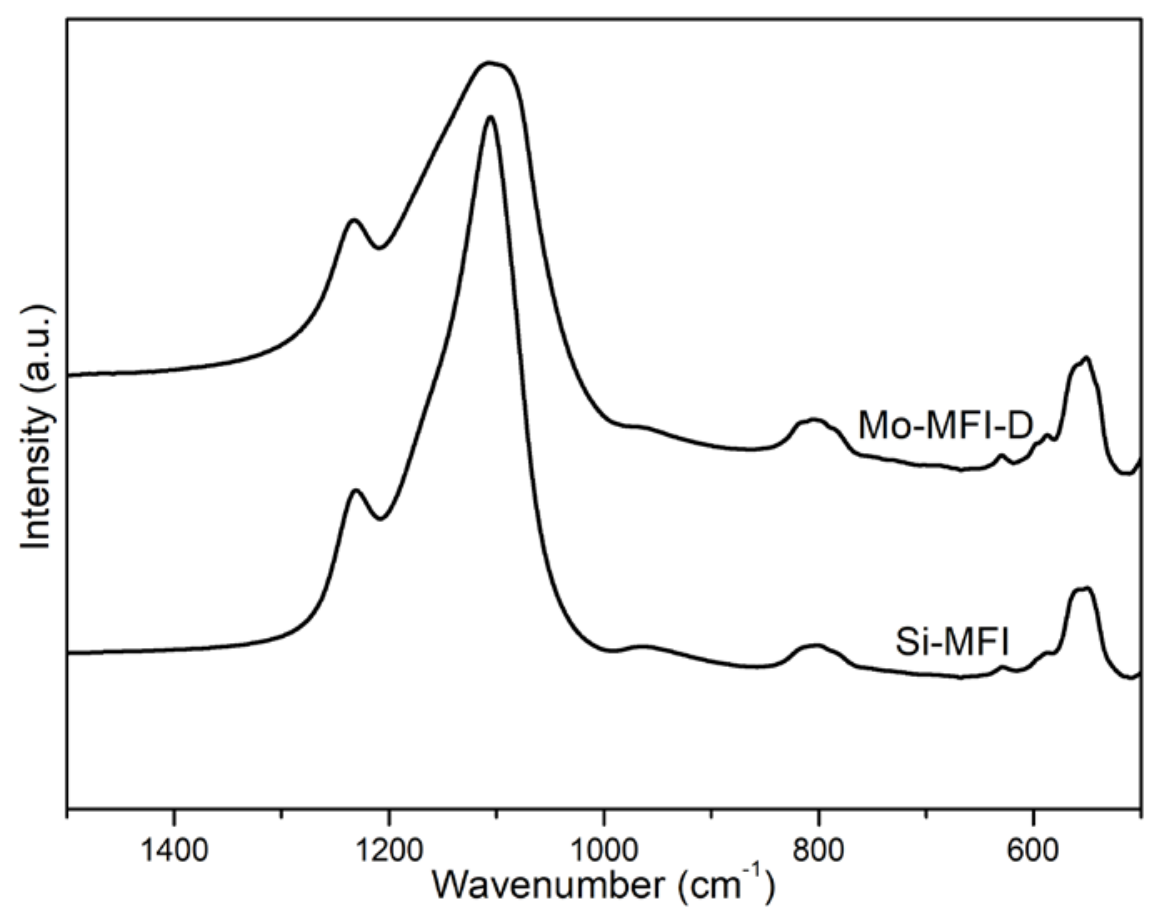

Figure S3. FTIR spectra of samples Mo-MFI-D and pure siliceous calcined MFI zeolite prior Mo introduction by ion exchange, measured using $\mathrm{KBr}$ technique. 


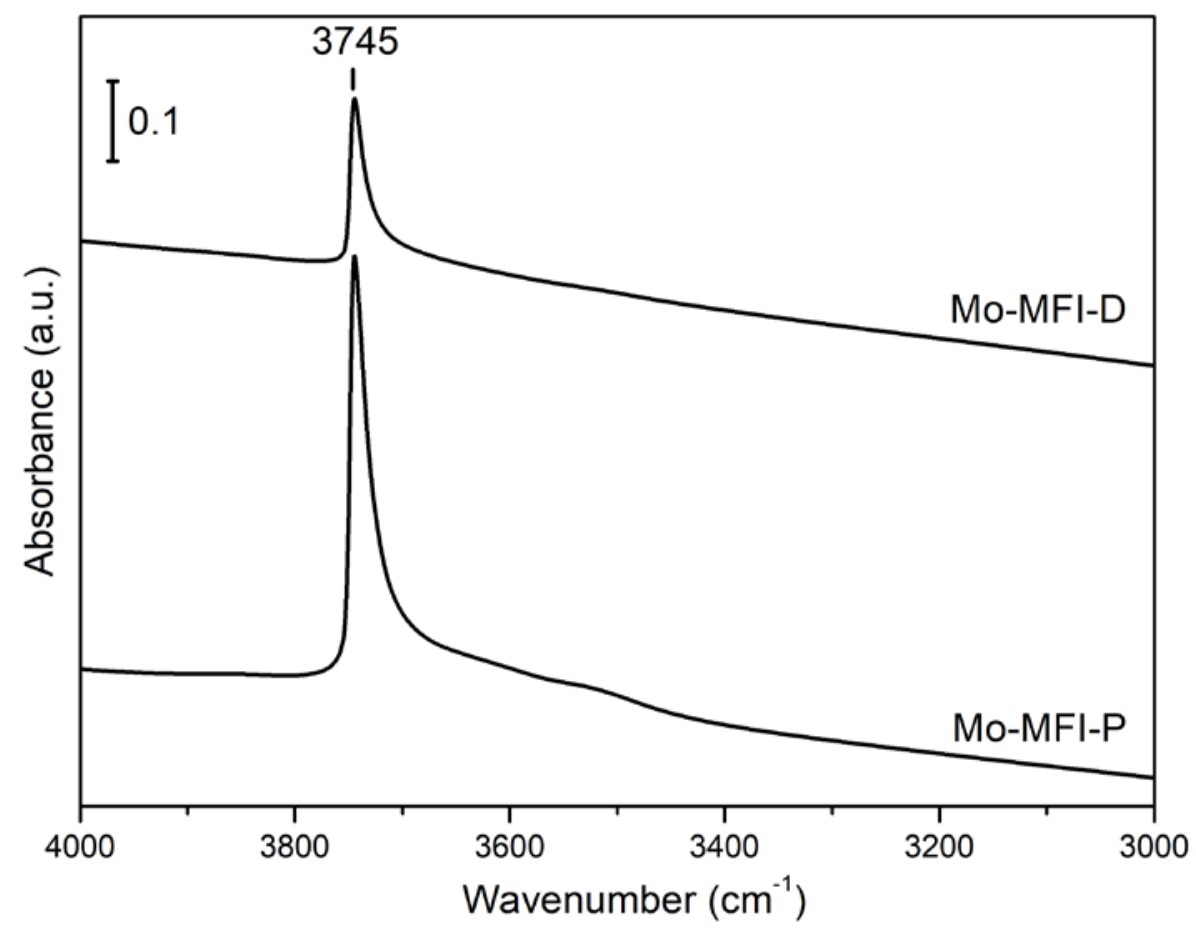

Figure S4. FTIR spectra of activated Mo-MFI-D and Mo-MFI-P samples $\left(480^{\circ} \mathrm{C}, 3 \mathrm{~h}\right)$ in the silanol region

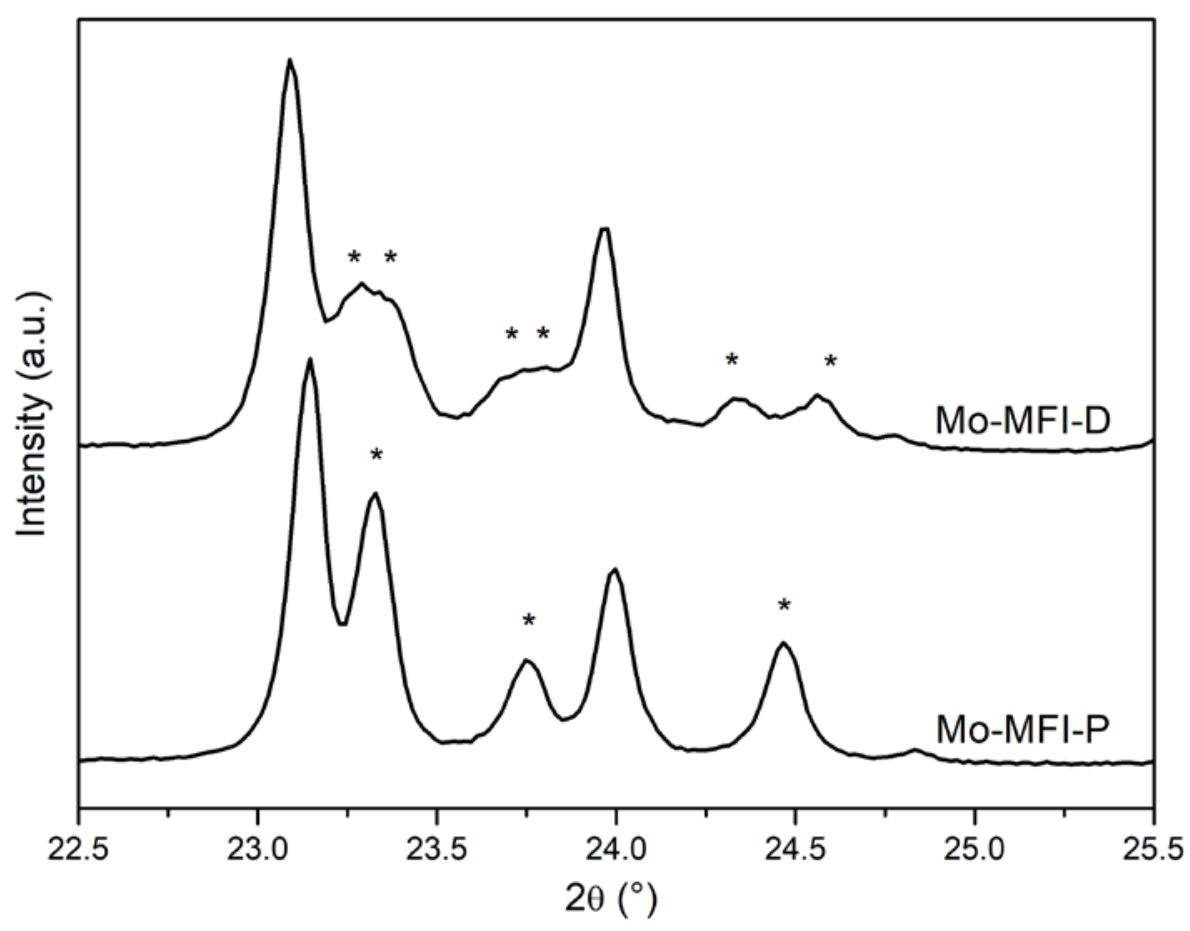

Figure S5. XRD patterns of Mo-MFI-D and Mo-MFI-P samples in the range of $22-26^{\circ} 2 \theta$ 

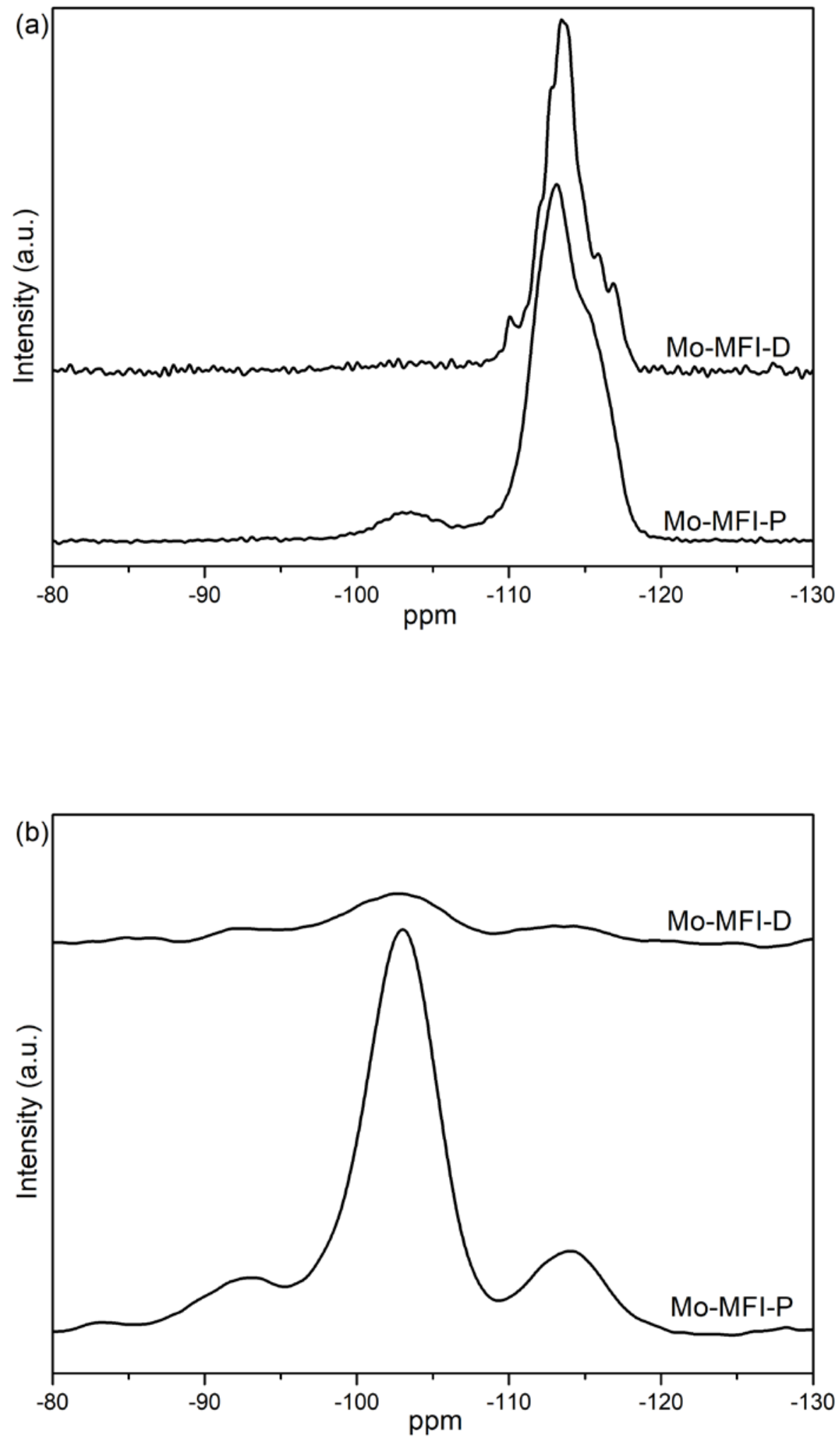

Figure S6. (a) ${ }^{29}$ Si MAS NMR and (b) $\mathrm{CP}\left\{{ }^{1} \mathrm{H}\right\}{ }^{29}$ Si MAS NMR spectra of samples Mo-MFI-P and Mo-MFI-D 
Table S1. Le Bail refinement results of samples Mo-MFI-D and Mo-MFI-P

\begin{tabular}{|c|c|c|c|c|c|c|c|c|c|}
\hline & Space group & $a(A)$ & $b(A)$ & $c(\mathbf{A})$ & $a\left({ }^{\circ}\right)$ & Volume $\left(A^{3}\right)$ & GOF $^{\mathrm{a}}$ & $R p^{b}$ & $w R^{c}$ \\
\hline I- & noclini & .121 & 9.902( & $3.386(8)$ & $90.528(7)$ & $5360.5(7)$ & 1.53 & 4.32 & 5.75 \\
\hline Io-MFI-P & Pnma (orthorhombic) & $20.061(2)$ & $19.898(4)$ & $13.370(8)$ & $90.000(0)$ & $5337.4(2)$ & 1.56 & 4.39 & 5.75 \\
\hline
\end{tabular}

${ }^{a}$ Goodness Of Fit

${ }^{\mathrm{b}}$ Expected R-factor

${ }^{c}$ Weight Profile R-factor

\section{References}

(1) Petřiček, V.; Dušek, M.; Palatinus, L. Crystallographic Computing System JANA2006: General Features. Z. Kristallogr. 2014, 229 (5), 345-352.

(2) Fung, B.M.; Khitrin, A.K.; Ermolaev, K. An Improved Broadband Decoupling Sequence for Liquid Crystals and Solids. J. Magn. Reson. 2000, 142 (1), 97-101.

(3) Bennett, A.E.; Griffin, R.G.; Ok, J.H.; Vega, S. Chemical Shift Correlation Spectroscopy in Rotating Solids: Radio Frequency-Driven Dipolar Recoupling and Longitudinal Exchange. J. Chem. Phys. 1992, 96 (11), 8624-8627. 